\title{
Cognitive functioning in major depression - a summary
}

\author{
Åsa Hammar ${ }^{1,2 *}$ and Guro Årdal \\ 1 Department of Biological and Medical Psychology, University of Bergen, Bergen, Norway \\ 2 Division of Psychiatry, Haukeland University Hospital, University of Bergen, Bergen, Norway
}

\author{
Edited by: \\ Kenneth Hugdahl, \\ University of Bergen, Norway \\ Reviewed by: \\ Anders Lund, University of Bergen, \\ Norway \\ Nils I. Landro, University of Oslo, \\ Norway

\section{*Correspondence} \\ Åsa Hammar, Department of Biological \\ and Medical Psychology, University of \\ Bergen, Jonas Lies vei 91, 5009 \\ Bergen, Norway. \\ e-mail: aasa.hammar@psybp.uib.no
}

\begin{abstract}
The aim of the present paper is to summarize the research during the past decade regarding cognitive functioning in Major Depressive Disorder (MDD). Cognitive impairment in the acute phase of illness has been frequently reported. The findings are shown in different cognitive domains, such as executive functions, attention, memory and psychomotor speed. Fewer reports have investigated cognitive functioning in MDD in longitudinal studies. Some longitudinal reports show that the impairment observed in the acute phase of illness may be long lasting despite symptom reduction and recovery. However, findings regarding cognitive functioning in depression are divergent. Factors that might contribute to the divergent findings, such as depression subtype, severity and comorbidity are discussed. Clinical implications and focus of future research directions is highlighted.In conclusion, depression is associated with cognitive impairment in the acute phase of illness, and some reports indicate that this impairment might be long lasting despite symptom reduction and recovery.
\end{abstract}

Keywords: major depression, cognitive functioning, impairment, acute phase, long-lasting

\section{INTRODUCTION}

MDD is the most prevalent of all mental disorders with an estimated life prevalence as high as $13.5-21.2 \%$ (Kessler and Walters, 1998; Turner and Gil, 2002; Kessler et al., 2005). Moreover, at any time as many as $5 \%$ of the population suffers from depression (Murphy et al., 2000). Together with schizophrenia, depression is responsible for $60 \%$ of all suicides worldwide and is predicted to be the second largest cause of disability in year 2020, for all ages and both genders (World Health Organization, [WHO], 2009). Regarding course of recovery it has been reported that only $20 \%$ of MDD patients recover and remain continuously well, while as many as $20 \%$ estimates to either commit suicide or always be incapacitated. The remaining $60 \%$ will recover but have further episodes (Hollon and Shelton, 2001).

Historically, MDD was seen as an episodic disorder but recent findings have indicated that developing a chronic course of the disease has been underestimated (Rush, 2001). MDD is associated with a high relapse risk, found to be highest during the first year after a depressive episode (Mueller et al., 1999). Moreover, 50\% of depressed patients experience a relapse within 2 years after their first episode, and $80 \%$ will experience more than one depressive episode during their life course (Mueller et al., 1999).

Due to the presented magnitude of this disorder, consequences are significant both at an individual level and for society. Disability in life functioning is a serious feature concerning Major Depressive Disorder (MDD) and a number of studies suggests that MDD is associated with significant disability and poorer quality of life (see review Papakostas et al., 2004). Numerous MDD patients experience that maintaining job performance at an acceptable level is difficult or impossible. Many have problems in fully participating in social and/or family life, and further they have problems in meeting other expectations from the society.

Although depression traditionally is seen as affective in nature, the last decades research have shown that depression is associated with a considerably and important disturbance in cognitive functioning.

\section{MATERIALS AND METHODS}

This summary is based on computerized searches of Medline, PsychINFO and PsychArticles, exclusively articles published since 2000, using the terms DEPRESSION/MAJOR DEPRESSION, COGNITIVE FUNCTION, ACUTE PHASE, LONGITUDINAL in combination. In addition reference lists were also examined for further relevant studies. This summary is not all-inclusive, the selection of articles reflects the authors evaluation of important themes in this area of research.

\section{COGNITIVE IMPAIRMENT IN DEPRESSIVE DISORDERS - EVIDENCE OVER THE PAST DECADE}

Research during the past decade has mainly focused on cognitive functioning in the severe phase of depression, and today it is widely accepted that the disease is characterized by cognitive impairment in the acute state (see review Austin et al., 2001; Taylor Tavares et al., 2003; see review Castaneda et al., 2008). There are reports of findings in different cognitive domains, such as executive functions $(\mathrm{EF})$, attention, memory and psychomotor speed (Austin et al., 2001; Castaneda et al., 2008).

\section{EXECUTIVE FUNCTIONING IN THE ACUTE PHASE OF ILLNESS}

There is no clear consensus regarding the definition of EF however, most studies have included components such as set-shifting, inhibition, working memory, fluency (Pennington and Ozonoff, 1996), planning and problem solving (Fossati et al., 2001) when measuring EF. Elliott (2003) defines EF as "complex cognitive processing requiring the co-ordination of several sub processes to achieve a particular goal". According to this view, EF are those involved in problem solving, modifying behavior in the light of new information, generating strategies or sequencing complex actions. Impairment in EF has been frequently reported in acute phase of MDD (see review Harvey et al., 2004; Rogers et al., 2004; Stordal et al., 2004) and deficits have been shown on tests measuring inhibition 
(Den Hartog et al., 2003; Markela-Lerenc et al., 2006; Gohier et al., 2009), problem solving and planning (Naismith et al., 2003), mental flexibility (Naismith et al., 2003; Airaksinen et al., 2004), verbal fluency (Reiches and Neu, 2000; Ravnkilde et al., 2002) decision making (Chamberlain and Sahakian, 2006) and working memory (Egeland et al., 2003b; Naismith et al., 2003; Rose and Ebmeier, 2006; Taylor Tavares et al., 2007), or the ability to inhibit one source of information and at the same time facilitate processing of another source of information (Hugdahl et al., 2009) (Table 1). More specifically it has been suggested that the inability to shift mental set is the most prominent EF impairment in MDD patients (Austin et al., 2001). Opposed to these findings, others have reported MDD patients to show normal performances in multiple aspects of EF (Grant et al., 2001; Landrø et al., 2001; Vythilingam et al., 2004; Stordal et al., 2005).

In sum, several studies have during the last decade presented firm evidence of EF impairment in the acute phase of depression, however factors contributing to the various impairment described in the literature must be indentified in a larger degree.

\section{ATTENTION DEFICITS IN THE ACUTE PHASE OF ILLNESS}

Several recent studies have reported MDD patients to show deficits on a variety of attention related tasks (Cohen et al., 2001; Landrø et al., 2001; Koetsier et al., 2002; Liu, et al., 2002; Ravnkilde et al., 2002; Hammar et al., 2003a; Porter et al., 2003; Lampe et al., 2004; Keilp et al., 2008; Simons et al., 2009) though the nature of the impairment is difficult to define as various studies investigate different aspects of this concept. Moreover, attention is closely related to other cognitive domains, especially psychomotor speed and EF. It has been suggested that attention can be divided into processing speed, selective attention and automatic processing; selective attention being a part of EF (Brebion et al., 2000; Egeland et al., 2003a), thus a frontal lobe function (Landrø et al., 2001). It has been shown that MDD patients are impaired on effortful attention related tasks, whereas normal performance is shown on automatic processing (Hammar, 2003; Hammar et al., 2003a).

It has been found that MDD patients show impairment on speeded measures however; remain unimpaired on selective attention (Pardo

Table 1 | Findings of impairment within the cognitive domain of EF in the acute phase of depression.

\begin{tabular}{ll}
\hline $\begin{array}{l}\text { Aspect of impairment in } \\
\text { the acute phase }\end{array}$ & References \\
\hline Inhibition & Den Hartog et al. (2003); \\
& Markela-Lerenc et al. (2006); \\
& Gohier et al. (2009); Hugdahl et al. (2009) \\
Problem solving and planning & Naismith et al. (2003) \\
Mental flexibility & Naismith et al. (2003); \\
& Airaksinen et al. (2004) \\
Verbal fluency & Reischies and Neu (2000); \\
& Ravnkilde et al. (2002) \\
Decision making & Chamberlain and Sahakian (2006) \\
Working memory & Egeland et al. (2003b); Naismith et al. \\
& (2003); Rose and Ebmeier (2006); \\
& Taylor Tavares et al. (2007)
\end{tabular}

et al., 2006). Further, there have been studies reporting no impairment in attention in mild to moderate MDD patients (Grant et al., 2001) or MDD patients (Harvey et al., 2004; Lampe et al., 2004). The divergent results reported in the domain of attention have been suggested to be caused by a too simple attention model that does not differentiate between processing speed on the one hand, and the ability to select relevant stimuli and resist distraction on the other (Egeland et al., 2003a).

In sum, impairment in attention related tasks is frequently reported in the acute phase of MDD. An important discussion is whether specific aspects of attention are more vulnerable, and what impact these attention deficits have for daily life functioning, treatment and recovery in this patient group.

\section{MEMORY DEFICITS IN THE ACUTE PHASE OF ILLNESS}

The cognitive domain of memory has been closely related to MDD. Memory is a complex concept involving several different processes. Consequently, various neuropsychological methods are used when different memory processes are investigated. Studies investigating memory have for instance distinguished between episodic and semantic memory, implicit and explicit memory and immediate and delayed memory, the latter being further divided into free and cued recall. Moreover, visual memory has usually been separated from verbal memory (Moscovitch, 1992).

Numerous studies have reported an association between MDD and memory impairments (Landrø et al., 2001; Fossati et al., 2002; Ravnkilde et al., 2002; Egeland et al., 2003b; Porter et al., 2003; Airaksinen et al., 2004; Campbell and MacQueen, 2004; Vythilingam et al., 2004; Matthews et al., 2008) (Table 2) however, the relationship is not clear. Studies have found MDD patients to be impaired in both verbal and visual memory (Reischies and Neu, 2000; Naismith et al., 2003), verbal delayed memory and verbal percent retention, however not in immediate verbal memory or visual memory (Vythilingam et al., 2004). Somewhat opposed to this, some have found immediate and delayed visuo-spatial memory to be impaired whilst immediate and long-term verbal declarative memory was preserved (Porter et al., 2003). Wang et al. (2006) found no impairment in first ever or recurrent depressed young adults compared to controls in verbal memory. Findings have also shown normal performance on tasks assessing verbal short-term memory and nonverbal long-term memory, whilst verbal working and long-term memory are impaired (Landrø et al., 2001). In contrast there are studies reporting primarily no impairment in MDD patients on tasks assessing memory (Grant et al., 2001; Barch et al., 2003; Den Hartog et al., 2003; Harvey et al., 2004).

In conclusion, memory impairment is frequently reported in the acute phase of MDD, however the nature and the mechanisms behind this impairment is somewhat unclear.

\section{NEUROPSYCHOLOGICAL PROFILE IN THE ACUTE PHASE}

Despite numerous of studies investigating cognitive functioning in MDD there is no agreement upon a conclusive neuropsychological profile characterizing depression. However, three hypotheses have been postulated in order to explain the cognitive impairment in this disorder. First, a global-diffuse hypothesis, which states that MDD patients show a generally lowered cognitive profile, suggesting a global-diffuse impairment on a range of cognitive domains (Veiel, 
Table 2 | Findings of impairment within the cognitive domain of memory in the acute phase of depression.

\begin{tabular}{ll}
\hline $\begin{array}{l}\text { Aspect of impairment } \\
\text { in the acute phase }\end{array}$ & References \\
\hline Verbal memory & \\
Visual memory & Naismith et al. (2003); \\
& Reischies and Neu (2000) \\
Verbal delayed memory & Naismith et al. (2003); \\
Visuo-spatial memory & Reischies and Neu (2000) \\
Verbal working memory & Vythilingam et al. (2004) \\
Verbal long term memory & Porter et al. (2003) \\
\hline
\end{tabular}

1997; Landrø et al., 2001). Secondly, a hypothesis of specific cognitive impairment, suggesting that MDD is associated with pronounced impairment within specific cognitive domains, foremost in EF and memory (Austin et al., 2001; Elliott, 2002). Thirdly, regardless of domain the cognitive effort hypothesis claims that MDD patients show impairment on effortful tasks whereas they show normal functioning on automatic tasks. Automatic processing is considered to be stimulus-driven, whilst effortful processing requires attention and cognitive capacity, and is also defined as an instruction-driven process (Hasher and Zacks, 1979; Hammar et al., 2003a).

The research over the past decade show diversity in findings; no single cognitive function has been found that characterizes all depressed patients, and not all patients are impaired in the same degree. However, there is firm evidence that depressed patients as a group are characterized by cognitive impairment in the acute phase. Diversity among findings might be explained by different methodological issues, such as inclusion of patients with different severity or subtypes of depression: in example bipolar disorder, first episode of major depression, recurrent episodes, depression with psychotic features, dysthymia, in patients versus out patients etc. In addition studies investigate different age groups, apply a variety of neuropsychological tests, and have different inclusion and exclusion criterion in example regarding medications and substance abuse. Co morbid disorders may play an important role in explaining diversity in findings across studies (Baune et al., 2009) in particular co morbid anxiety (see review Levin et al., 2007). When these factors are mixed within studies, it is difficult to subtract the core of the neuropsychological impairment in depression. In example, there is strong reason to believe that first ever depressed patients might show a different cognitive profile than recurrent depressed patients. It can be difficult to determine whether a person is experiencing a first ever depressive episode, thus a throughout diagnostic screening should be a part of inclusion. All these factors might influence results and cause difficulties in agreement upon a neuropsychological profile that characterize depression in the acute phase of illness. It is highly likely that different subgroups of depressed samples show different patterns of impairment. In addition, Scheurich et al. (2008) have suggested that the cognitive impairment associated with depression can be influenced by motivational aspects. Such knowledge would further be of importance for the treatment course of depression.
Although cognitive impairment in the acute phase of MDD is well documented, the knowledge of how the impairments develop in a long-term perspective is scant. A major question, with implications for our understanding of MDD, is whether cognitive impairment manifested during periods of depression is long lasting or improves during remission and recovery.

\section{DEPRESSION AND LONG-LASTING COGNITIVE IMPAIRMENT - A NEW FIELD OF INTEREST}

A common understanding early in the literature and in clinical practice has been that cognitive impairment restores as depression heals. This assumption has been questioned the last decade. The association between cognitive function and MDD in a long-term perspective has seldom been investigated, thus longitudinal studies on this topic are few and results are divergent. Knowledge in this area is therefore limited, and there are still numerous questions regarding how cognitive functioning evolves in relation to symptom reduction and remission (Figure $\mathbf{1}$ ).

Of the longitudinal studies existing on this field several indicates that cognitive impairment seen during episodes of illness, also persists during episodes of symptom reduction (Hammar et al., 2003b; Airakinsen et al., 2006) and even in remission (Reischies and Neu, 2000; Majer et al., 2004; Weiland-Fiedler et al., 2004; Neu et al., 2005; Paelecke-Habermann et al., 2005; Smith et al., 2006; Gruber et al., 2007; Nakano et al., 2008), although some studies report no such findings (Koetsier et al., 2002; Biringer et al., 2005; Lahr et al., 2007). Other studies suggests that cognitive impairment worsens for every episode of depression (Brown et al., 1999; Sweeney et al., 2000) and that impairment observed in a nonsymptomatic phase is related to number of previous episodes of depression (Kessing, 1998). It is possible that prolonged cognitive impairment holds true for sub groups of depressed samples, thus not all patients are characterized by long-lasting impairment.

Hammar et al. (2003b) found that depressed patients showed impaired cognitive performance on cognitive demanding tasks (effortful processing) when symptomatic and that the impairment prevails after 6 months, despite significant improvement in the depression symptoms.

Studies investigating patients in remission has shown longlasting impairment in various of cognitive functions, such as sustained attention (Majer et al., 2004; Weiland-Fiedler et al., 2004), attention and Executive Functioning (Paelecke-Habermann et al., 2005), Verbal memory and verbal fluency (Reischies and Neu, 2000; Neu et al., 2005), Executive Functioning (Smith et al., 2006; Gruber et al., 2007; Reppermund et al., 2009).

In contrast a 2-year follow-up study reported a correlation between improvement in depressive symptoms and improvement in EF, suggesting that depression related changes in EF are reversible upon remission (Biringer et al., 2005). However, MDD patients failed to improve to the level of controls at follow-up on some EF measures, and the observed improvement in the depressed patient group could be due to a general training effect which was not controlled for because of missing control group at follow up.

Gualtieri et al. (2006) found that MDD patients who are successfully treated with newer antidepressants are better cognitively than untreated patients. However, the performance was still worse than healthy controls. 


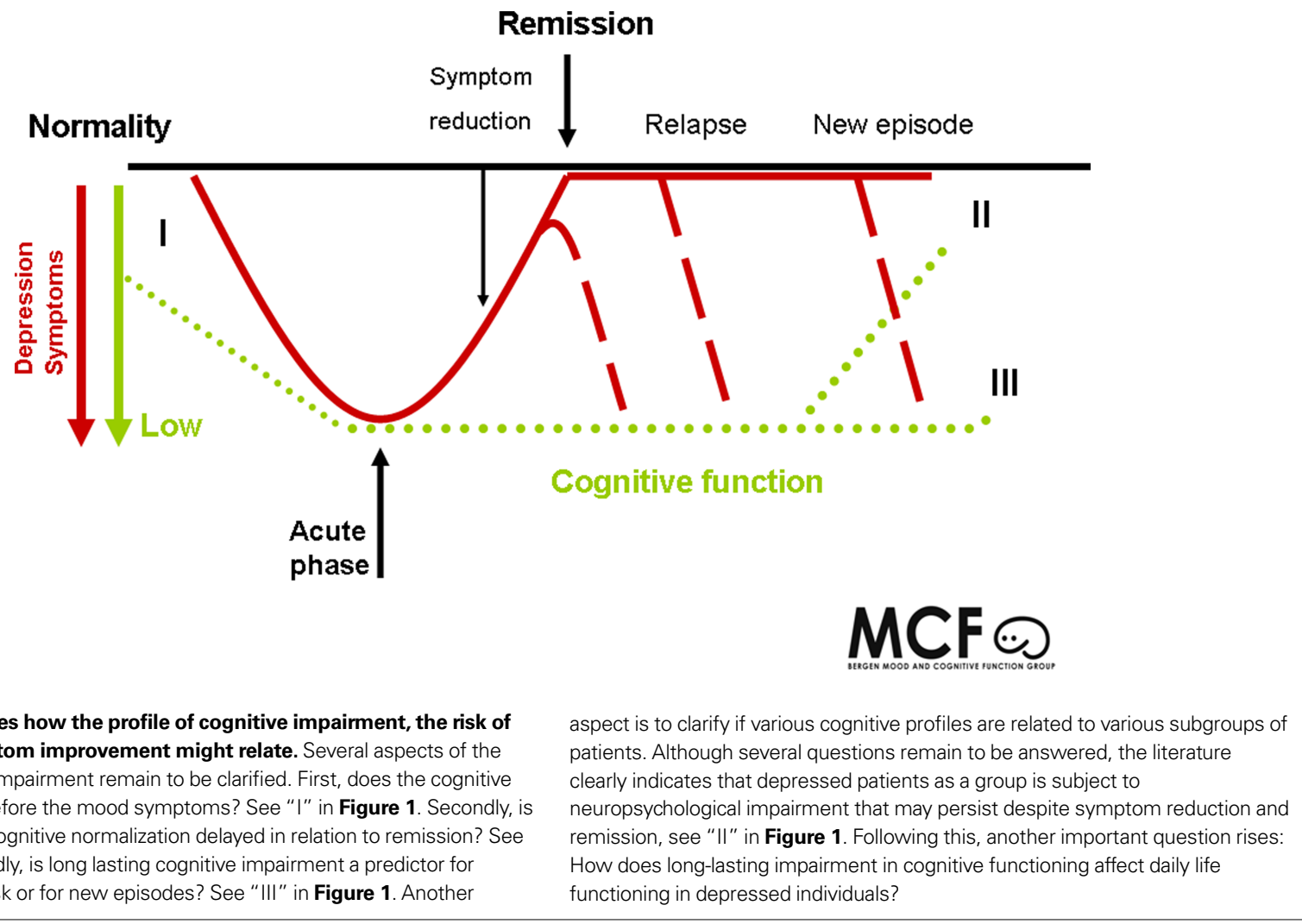

Regarding the relation between MDD and long-term cognitive functioning two different hypotheses have been proposed. Based on earlier findings the first hypothesis suggests that cognitive impairment sustains despite symptom reduction (Martinez-Aran et al., 2000; Reischies and Neu, 2000; Austin et al., 2001; Hammar et al., 2003b). The second hypothesis states that multiple depressive episodes further deteriorate cognitive impairment (Sweeney et al., 2000). There is, however, increasing indications in the recent literature that symptom reduction in depressions is not followed by cognitive improvement to a similar degree.

\section{IMPAIRMENT IN DAILY LIFE FUNCTIONING}

Depression is associated with impairment in daily life functioning (see review Papakostas et al., 2004). Several studies have investigated how depression affects daily life functioning in the acute phase of illness, thus the knowledge on this field is rather conclusive. Studies have shown that MDD affects several aspects of work performance, including productivity, task focus and days absent caused by sickness (Wang et al., 2004; Adler et al., 2006). A central aspect of life functioning is family and social relations, again shown to be impaired in depressive patients, including household strain, social irritability, financial strain, limitations in occupational functioning and poor health status (see review Papakostas et al., 2004).

Traditionally, mood symptoms have been used to explain this disability in life functioning in mood disorders. However findings indicate that improvement in daily life functioning does not follow improvement in depression symptoms to a similar degree (Adler et al., 2006; Kennedy et al., 2007). Daily life functioning has been found to be impaired even in phases of remission of depression (Angermeyer et al., 2002; Jaeger et al., 2006). Different factors could explain why improvement in depressive symptoms is not followed by improvement in daily life functioning to a similar extent. Residual symptoms, comorbidity, misdiagnosis and long-lasting cognitive impairment could be important factors associated with long-lasting impairment in daily life functioning (Kennedy et al., 2007).

Studies have found that cognitive impairment play an important role in functional recovery from depression (Jaeger et al., 2006). This has also been reported regarding bipolar disorder (MartinezAran et al., 2007).

The lack of knowledge on this field regarding the possible impact long-lasting cognitive impairment represents for daily life functioning in this patient group is strikingly. And there is only few studies investigating this question. This possible relationship has enormous clinical implications.

\section{CLINICAL IMPLICATIONS}

Remitted MDD patients are often expected to function at a premorbid level. However, this might not be a rightful expectation if cognitive functioning and daily life functioning is impaired in a long time course after depression. The results of this expectation may lead to frustration, low self esteem, low coping, and feelings of worthlessness for the individual involved, and in a worst case enhance the risk of relapse. Patients cognitive functioning and the impact this has on daily life functioning should be a focus in ongoing treatment. Impaired cognitive functioning affects family life, school performance, work performance and social 
life. Cognitive training and rehabilitation could prove important in treating depression in the long-term course, and help prevent relapse. And important challenge is to unite research and practice, and it is of great importance that the possible long-lasting cognitive impairment associated with depression is debated in clinical settings.

\section{FUTURE STUDIES}

Cognitive impairment may be an enduring component of a chronic depression (Kennedy et al., 2007). It is evident that increased focus on longitudinal studies is necessary if the relation between MDD and cognitive function shall be further explored and understood, this mainly to improve rehabilitation conditions and prevent relapses. One of the main questions that must be further investigated is if long-lasting cognitive impairment is a risk factor for relapse episodes. If so, will cognitive training and rehabilitation be possible treatments in order to prevent new episodes. These types of questions are in today's literature still unsolved.

Moreover, MDD patients in general are a heterogeneous group and there is reason to believe that the degree of cognitive impairment is related to clinical factors such as numbers of previous episodes, duration, onset as well as treatment factors like effects of medications and hospitalization. There are many distinct combinations of symptoms that would qualify for a diagnosis. Thus, this implicates that future studies must aim to include homogenous patient groups and differ between factors such as degree of severity as well as between first episode patients, patients with recurrent episodes, bipolar diagnosis etc. Following this, an important challenge for future studies is homogenous patient groups with

well described inclusion and exclusion criterion. This would make comparison across studies more precise, thus possibly answer the question of divergent findings.

Future research will have the possibility to clarify questions regarding the impact cognitive functioning in MDD patients have on life functioning in a long-term course. It is important to make clear this relationship because of the impact this might have on recovery, treatment course and outcome of the disease. Improving cognitive functioning, in example trough cognitive rehabilitation, might show crucial for work performance and occupational life in this patient group and also help patients in the therapeutic process. Identifying risk factors for relapses and new episode is of great importance in order to reduce the burden of MDD worldwide.

\section{CONCLUDING REMARKS}

During the past decade much research has focused on cognitive function in MDD, and impairment in cognitive functioning in the acute phase of illness is well documented. Less is known about the course of this impairment and several questions remain unanswered. Some studies report the impairment observed in the acute phase to be long lasting, and also persistent in phases of remission. However, there are contradictory findings on this field which might indicate that this holds true in subgroups of depressed patients, thus not describe all MDD patients. In particular there is a lack of studies investigating these questions in first ever depressed samples, and longitudinal studies following patients over several years. There is a need for studies investigating cognitive functioning in well defined homogenous patient groups longitudinally in the future.

Adler, D. A., McLaughlin, T. J., Rogers, W. H., Chang, H., Lapitsky, L., and Lerner, D. (2006). Job performance deficits due to depression. Am. J. Psychiatry 163, 1569-1576.

Airaksinen, E., Larsson, M., Lundberg, I., and Forsell, Y. (2004). Cognitive functions in depressive disorders: evidence from a population-based study. Psychol. Med. 34, 83-91.

Airakinsen, E., Wahlin, Å., Larsson, M., and Forsell, Y. (2006). Cognitive and social functioning in recovery from depression: results from a populationbased three-year follow-up. J. Affect. Disord. 96, 107-110.

Angermeyer, M. C., Holzinger, A., Matschinger, H., and StenglerWenzke, K. (2002). Depression and quality of life: results of a followup study. Int. J. Soc. Psychiatry 48, 189-199.

Austin, M. P., Mitchell, P., and Goodwin, G. M. (2001). Cognitive deficits in depression: possible implications for functional neuropathology. $\mathrm{Br}$. J. Psychiatry 178, 200-206.

Barch,D.M.,Sheline,Y.I.,Csernansky J. G., and Snyder, A. Z. (2003). Working memory and prefrontal cortex dysfunction: specificity to schizophrenia compared with major depression Biol. Psychiatry 53, 376-384.

Baune, B. T., McAfoose, J., Leach, G. Quirk, F., and Mitchell, D. (2009). Impact of psychiatric and medical comorbidity on cognitive function in depression. Psychiatry Clin. Neurosci. 63, 392-400.

Biringer, E., Lundervold, A., Stordal, K. I., Mykletun,A., Egeland,J., Bottlender, R., and Lund, A. (2005). Executive function improvement upon remission of unipolar major depression. Eur. Arch. Psychiatry Clin. Neurosci. 255, 373-380.

Brebion, G., Smith, M. J., Gorman, J. M., Malaspina, D., Sharif, Z., and Amador X. (2000). Memory and schizophrenia: differential link of processing speed and selective attention with two levels of encoding. J. Psychiatr. Res. 34, 121-127.

Brown, E. S., Rush,A.J., and McEwen, B. S. (1999). Hippocampal remodeling and damage by corticosteroids: implications for mood disorders. Neuropsychopharmacology $21,474-484$.

Campbell, S., and MacQueen, G. (2004). The role of the hippocampus in the profile in schizophrenia compared pathophysiology of major depression J. Psychiatry Neurosci. 29, 417-426.

with depression: differential effects of processing speed, selective attention and vigilance. Acta Psychiatr. Scand. 108, 276-284.

, Suvisaari, J, and Lönnquist, J. A. (2008). A review on cognitive impairments in depressive and anxiety disorders with a focus on young adults. J. Affect. Disord. 106, $1-27$.

Chamberlain, S. R., and Sahakian, B. J. (2006). The neuropsychology of mood disorders. Curr. Psychiatry Rep. $8,458-463$.

Cohen, R., Lohr, I., Paul, R., and Boland, R. (2001). Impairments of attention and effort among patients with major affective disorders. J. Neuropsychiatry Clin. Neurosci. 13, 3 .

Den Hartog, H. M., Derix, M. M. A., Van Bemmel, A. L., Kremer, B., and Jolles, J. (2003). Cognitive functioning in young and middle - aged unmedicated out - patients with major depression: testing the cognitive effort and cognitive speed hypothesis. Psychol. Med. 33, 1443-1451.

Egeland, J., Rund, B. R., Sundet, K. Landrø, N. I., Asbjørnsen, A., Lund, A., Roness, A., Stordal, K. I. and Hugdahl, K. (2003a). Attention
Egeland, J., Sundet, K., Rund, B. R., Asbjørnsen, A., Hugdahl, K., Landrø, N. I., Lund, A., Roness, A., and Stordal, K. I. (2003b). Sensitivity and specificity of memory dysfunction in schizophrenia: a comparison with major depression. Neuropsychol. Dev. Cogn. A. J. Clin. Exp. Neuropsychol. 25, 79-93.

Elliott, R. (2002). The neuropsychological profile in primary depression. In Cognitive Deficits in Brain Disorders, J. E. Harrison and O. A. M., eds (London, Martin Dunitz), p. 370

Elliott, R. (2003). Executive functions and their disorders. Br. Med. Bull. 65, 49-59.

Fossati, P., Coyette, F., Ergis, A.-M., and Allilaire, J.-F. (2002). Influence of age and executive functioning on verbal memory of inpatients with depression. J. Affect. Disord. 68, 264-271.

Fossati, P., Ergis, A., and Allilaire, J. (2001). Problem-solving abilities in unipolar depressed patients: comparison of performance on the modified version of the Wisconsin and the California sorting tests. Psychiatry Res. 104, 145-156. 
Gohier, B., Ferracci, L., Surguladze, S. A., Lawrence, E., El Hage, W., Kefi, M. Z. Allain, P., Garre, J. B., and LeGall, D. (2009). Cognitive inhibition and working memory in unipolar depression. J. Affect. Disord. 116, 100-105.

Grant, M., Thase, M., E., and Sweeney, J. A. (2001). Cognitive disturbance in outpatient depressed youngeradults: evidence of modest impairment. Biol. Psychiatry 50, 35.

Gruber, S., Rathgeber, K., Braunig, P., and Gauggel, S. (2007). Stability and course of neuropsychological deficits in manic and depressed bipolar patients compared to patients with major depression. J. Affect. Disord. 104, 61-71.

Gualtieri, T. C., Johnson, L. G., and Benedict, K. B. (2006). Neurocognition in depression: Patients on and off medication versus healthy comparison subjects. J. Neuropsychiatry Clin. Neurosci. 18, 217-225.

Hammar, $\AA$. (2003). Automatic and effortful information processing inunipolar major depression. Scand. J. Psychol.44, 409-413.

Hammar, A., Lund, A., and Hugdahl, K. (2003a). Selective impairment in effortful information processing in major depression. J. Int. Neuropsychol. Soc. 9, 954-959.

Hammar, Å., Lund, A., and Hugdahl, K. (2003b). Long-lasting cognitive impairment in unipolar major depression: a six months follow-up study. Psychiatry Res. 118, 189-196.

Harvey, P. O., Le Bastard, G., Pochon, J. B., Levy, R., Allilaire, J. F., Dubois, B., and Fossati, P. (2004). Executive functions and updating of the contents of working memory in unipolar depressions. J. Psychiatr. Res. 38, 567-576.

Hasher, L., and Zacks, R. T. (1979). Automatic and effortful processes in memory. J. Exp. Psychol. Gen. 108, 356-388.

Hollon, S. D., and Shelton, R. C. (2001). Treatment guidelines for major depressive disorder. Behav. Ther. 32, 235-258.

Hugdahl, K., Westerhausen, R., Alho, K., Medvedev, S., Laine, M., and Hämäläinen. H. (2009). Attention and cognitive control: unfolding the dichotic listening story. Scand. J. Psychol. 50, 11-22.

Jaeger, J., Berns, S., Uzelac, S., and DavisConway, S. (2006). Neurocognitive deficits and disability in major depressive disorder. Psychiatry Res. 145, 39-48.

Keilp, J. G., Gorlyn, M., Oquendo, M. A., Burke, A. K., and Mann, J. J. (2008). Attention deficit in depressed suicide attempters. Psychiatry Res. 159, 7-17.

Kennedy, N., Foy, F., Sherazi, R., McDonough, M., and McKeon, P.
(2007). Long-term social functioning after depression treated by psychiatrists: a review. Bipolar Disord. 9, 25-37.

Kessing, L. V. (1998). Cognitive impairment in the euthymic phase of affective disorder. Psychol. Med. 28, 1027-1038.

Kessler, R. C., Berglund, P., Demler, O., Jin, R., Merikans, K. R., and Walters, E. E. (2005). Lifetime prevalence and age-of-Onset distributions of DSM-IV disorder in the national comorbidity survey replication. Arch. Gen. Psychiatry 62, 593-768.

Kessler, R. C., and Walters, E. E. (1998). Epidemiology of DSM-III-R major depression and minor depression among adolescents and young adults in the National Comorbidity Survey. Depress. Anxiety 7, 3-14.

Koetsier, G. C., Volkers, A. C., Tulen, J. H. M., Passchier, J., van den Broek, W. W., and Bruijn, J. A. (2002). CPT performance in major depressive disorder before and after treatment with fluvoxamine. J. Psychiatr. Res. 36, 391-397.

Lahr, D., Beblo, T., and Hartje, W. (2007). Cognitive performance and subjective complaints before and after remission of major depression. Cogn. Neuropsychiatry 12, 25-45.

Lampe, K. I., Sitskoorn, M. M., and Heeren, T. J. (2004). Effects of recurrent major depressive disorder on behavior and cognitive function in female depressed patients. Psychiatry Res. 125, 73-79.

Landrø, N. I., Stiles, T. C., and Sletvold H. (2001). Neuropsychological function in nonpsychoticunipolar major depression. Neuropsychiatry Neuropsychol. Behav. Neurol. 14, 233-240.

Levin, R. L., Heller, W., Mohanty, A., Herrington, J. D., and Miller, G. A. (2007). Cognitive deficits in depression and functional specificity of regional brain activity. $\operatorname{Cogn}$. Ther. Res. 31, 211-233.

Liu, S. K., Chiu, C. H., Chang, C. J., Hwang, T. J., Hwu, H. G., and Chen, W. J. (2002). Deficits in sustained attention in schizophrenia and affective disorders: stable versus statedependent markers. Am. J. Psychiatry 159, 975-982.

Majer, M., Ising, M., Kunzel, H., Binder, E. B., Holsboer, F., Modell, S., and Zihl, J. (2004). Impaired divided attention predicts delayed response and risk to relapse in subjects with depressive disorders. Psychol. Med. 34, 1453-1463.

Markela-Lerenc, J., Kaiser, S., Fiedler, P., Weisbrod, M., and Mundt, C. (2006). Stroop performance in depressive patients: a preliminary report. J.Affect. Disord. 94, 261-267.

Martinez-Aran, A., Vieta, E., Colom, F., Reinares, M., Benabarre, A., Gasto, C., and Salamero, M. (2000). Cognitive dysfuctions in bipolar disorder: evidence of neuropsychological disturbances. Psychother. Psychosom. 69, 2-18.

Martinez-Aran, A., Vieta, E., Torrent, C., Sanchez-Moreno, J., Goikolea, J. M., Salamero, M., Mahli, G. S., GonzalesPinto, A., Daban, C., Alvarez-Grandi, S., Fountoulakis, K., Kaprinis, G., Tabares-Seisdedos, R., and AyusoMateos, J. L. (2007). Functional outcome in bipolar disorder: the role of clinical and cognitive factors. Bipolar Disord. 9, 103-113.

Matthews, K., Coghill, D., and Rhodes, S. (2008). Neuropsychological functioning in depressed adolescent girls. J. Affect. Disord. 111, 113-118.

Moscovitch, M. (1992). Memory and working-with-memory: a component process model based on modules and central systems. J. Cogn. Neurosci. 4 , 257-267.

Mueller, T. I., Leon, A. C., Keller, M. B., Solomon, D. A., Endicott, J., Coryell, W., Warshaw, M., and Maser, J. D. (1999). Recurrence after recovery from major depressive disorder during 15 years of observational follow-up. Am J. Psychiatry 156, 1000-1006.

Murphy,J.M., Laird, N.M., Monson, R. R., Sobol, A. M., Leighton, A. H. (2000) 40-year perspective on the prevalence of depression. The Stirling County Study. Arch. Gen. Psychiatry 57, 209-215.

Naismith, S. L., Hickie, I. B., Turner, K., Little, C. L., Winter, V., Ward, B. P. Wilhelm, K., Mitchell, P., and Parker G. (2003). Neuropsycholgical performance in patients with depression is associated with clinical, etiological and genetic risk factors. J. Clin. Exp. Neuropsychol. 25, 866-877.

Nakano, Y., Baba, H., Maeshima, H., Kitajima, A., Sakai, Y., Baba, K., Suzuki, T., Mimura, M., and Arai, H. (2008). Executive dysfunction in medicated, remitted state of major depression. J. Affect. Disord. 111, 46-51.

Neu, P., Bajbouj, M., Schilling, A., Godemann, F., Berman, R., and Schlattmann, P. (2005). Cognitive function over the treatment course of depression in middle-aged patients: correlation with brain MRI signal hyperintensities. J. Psychiatr. Res. 39, 129-135.

Paelecke-Habermann, Y., Pohl, J., and Leplow, B. (2005). Attention and executive functions in remitted major depression patients. J. Affect. Disord. $89,125-135$.
Papakostas, G. I., Petersen, T., Mahal, Y., Mischoulon, D., Nierenberg A. A., and Fava, M. (2004). Quality of life assessments in major depressive disorder: a review of the literature. Gen. Hosp. Psychiatry 26, 13-17.

Pardo, J.V., Pardo, P. J., Humes, S. W., and Posner, M. I. (2006). Neurocognitive dysfunction in antidepressant-free non - elderly patients with unipolar depression: alerting and convert orienting of visuospatial attention. J. Affect. Disord. 92, 71-78.

Pennington, B. F., and Ozonoff, S. (1996). Executive functions and developmental psychopathology. J. Child. Psychol. Psychiatry 37, 51-87.

Porter,R. J., Gallagher, P., Thompson, J. M., andYoung,A.H.(2003).Neurocognitive impairment in drug-free patients with major depressive disorder. $\mathrm{Br}$. J. Psychiatry 182, 214-220.

Ravnkilde, B., Videbech, P., Clemmensen, K., Egander, A., Rasmussen, N. A., and Rosenberg, R. (2002). Cognitive deficits in major depression. Scand. J. Psychol. 43, 239-251.

Reischies, F. M., and Neu, P. (2000). Comorbidity of mild cognitive disorder and depression - a neuropsychological analysis. Eur. Arch. Psychiatry Clin. Neurosci. 250, 186-193.

Reppermund, S., Ising, M., Lucae, S., and Zihl, J. (2009). Cognitive impairment in unipolar depression is persistent and non-spesific: further evidence for the final common pathway disorder hypothesis. Psychol. Med. 39, 603-614.

Rogers, M. A., Kasai, K., Koji, M. Fukuda, R.,Iwanami,A., Nakagome, K., Fukuda, M., and Nobumasa, K. (2004). Executive and prefrontal dysfunction in unipolar depression: a review of neuropsychological and imaging evidence. Neurosci. Res. 50, 1-11.

Rose, E. J., and Ebmeier, K. P. (2006). Pattern of impaired working memory during major depression. J. Affect. Disord. 90, 149-161.

Rush, A. J. (2001). Chronic major depression: a review and update. J. Clin. Psychiatry 62(Suppl. 6), 3-4.

Scheurich, A., Fellgiebel, A., Schermuly, I., Bauer,S., Wölfges, R., and Müller, M. J. (2008). Experimental evidence for a motivational orgin of cognitive impairment in major depression. Psychol. Med. 38, 237-246.

Simons, C. J. P., Jacobs, N., Derom, C., Thiery, E., Jolles, J., van Os, J., and Krabbendam, L. (2009). Cognition as a predictor of current and follow up depressive symptoms in the general population. Acta Psychiatr. Scand. 120, 45-52. 
Smith, D. J., Muir, W. J., and Blackwood, D. H. (2006). Neurocognitive impairment in euthymic young adults with bipolar spectrum disorder and recurrent major depressive disorder. Bipolar Disord. 8, 40-46.

Stordal, K. I., Lundervold, A., Egeland, J., Mykletun, A., Asbjørnsen, A., Landrø, N. I., Roness, A., Rishovd Rund, B., Sundet, K., Oedegaard, K. J., and Lund, A. (2004). Impairment across executive functions in recurrent major depression. Nord. J. Psychiatry $58,41-47$.

Stordal, K. I., Lundervold,A., Mykletun,A., Asbjørnsen, A., Biringer, E., Egeland, J. Hammar, Å., Landrø, N. I., Roness, A., Rund, B. R., Sundet, K., and Lund, A. (2005). Frequency and characteristics of recurrent major depressed patients with unimpaired executive functions. World J. Biol. Psychiatry 6, 36-44.

Sweeney, J.A., Kmiec,J.A., and Kupfer, D. J. (2000). Neuropsychologic impairments in bipolar and unipolar mood disorders on the CANTAB neurocognitive battery. Biol. Psychiatry 48, 674-684.

Taylor Tavares, J. V., Clark, L., Cannon, D. M., Erickson, K., Drevets, W. C., and Sahakian, B. J. (2007). Distinct profiles of neurocognitive function in unmedicated unipolar depression and bipolar II depression. Biol. Psychiatry 15, 917-924.

Taylor Tavares, J. V., Drevets, W. C., and Sahakian, B. J. (2003). Cognition in mania and depression [Editorial]. Psychol. Med. 33, 959-967.

Turner, J. R., and Gil, A. G. (2002). Psychiatric and substance use disorders in South Florida racial/ethnic and gender contrasts in a young adult cohort. Arch. Gen. Psychiatry. 59, 43-50.

Veiel,H.O.F.(1997).A preliminary profile of neuropsychological deficits associated with major depression. J. Clin. Exp. Neuropsychol. 19, 587-603.

Vythilingam, M., Vermetten, E., Anderson, G. M., Luckenbaugh, D.
Anderson, E. R., Snow, J., Staib, L. H. Charney, D. S., and Bremmer, D. (2004). Hippocampal volume, memory, and cortisol status in major depressive disorder: effects of treatment. Biol. Psychiatry 56, 101-112.

Wang, C. E., Halvorsen, M., Sundet, K. Steffensen, A. L., Holte, A., and Waterloo, K. (2006). Verbal memory performance of mildly to moderately depressed outpatient younger adults. J. Affect. Disord. 92, 283-286.

Wang P. S., Beck, A. L., Berglund, P., McKenas, D. K., Pronk, N.P., Simon, G. E., and Kessler, R. C. (2004). Effects of major depression on moment-in-time work performance. Am. J. Psychiatry 161, 1885-1891.

Weiland-Fiedler, P., Erickson, K., Waldeck, T., Luckenbaugh, D. A., Pike, D., Bonne, O., Charney, D. S. and Neumeister, A. (2004). Evidence for continuing neuropsychological impairments in depression. J. Affect. Disord. 82, 253-258.
WHO (2009). Available at: http://www. who.int/mental_health/management/ depression/definition/en/

Conflict of Interest Statement: The authors declare that the research was conducted in the absence of any commercial or financial relationships that could be construed as a potential conflict of interest.

Received: 27 May 2009; paper pending published: 03 August 2009; accepted: 02 September 2009; published online: 25 September 2009.

Citation: Hammar $\AA$ and Årdal G (2009) Cognitive functioning in major depression - a summary. Front. Hum. Neurosci. 3:26. doi: 10.3389/neuro.09.026.2009 Copyright $\odot 2009$ Hammar and Årdal. This is an open-access article subject to an exclusive license agreement between the authors and the Frontiers Research Foundation, which permits unrestricted use, distribution, and reproduction in any medium, provided the original authors and source are credited. 